\title{
Research on the Effect of Supervisor Feedback for Undergraduate Thesis Writing
}

\author{
Shuangyun Jiang ${ }^{1} \&$ Xiaoqin Yan $^{1}$ \\ ${ }^{1}$ Foreign Languages College, Jiangxi Normal University, Jiangxi, China \\ Correspondence: Shuangyun Jiang, Foreign Languages College, Jiangxi Normal University (JXNU), Nanchang, \\ Jiangxi, China.
}

Received: November 14, 2019

Accepted: December 5, 2019

Online Published: December 9, 2019

doi: 10.5539/elt.v13n1p43

URL: https://doi.org/10.5539/elt.v13n1p43

\begin{abstract}
The guidance effect of teacher feedback in contemporary English writing has been a hot topic for research. More and more researches focus on the effect of teacher feedback in senior high schools or universities. This research analyzed the supervisor feedback on 32 undergraduate thesis revisions from 8 students from three aspects: error feedback, non-error feedback and the focus of supervisor feedback. The results show that both error feedback and non-error feedback can significantly improve the overall expression of papers; while their focuses are quite distinctive. Suggestions on how to optimize teacher feedback are put forward.
\end{abstract}

Keywords: supervisor feedback, error feedback, non-error feedback, feedback focus

\section{Introduction}

Feedback is essential in interactive activities in second language learning and also fundamental in process writing; teacher feedback is a hot but controversial issue in second language writing research.

Keh (1990) regards feedback as input from a reader to a writer to provide information for the writer's revision, usually reflected as the comments, questions, and suggestions a reader gives a writer. Truscott (2007) considered error-correcting feedback as ineffective, even harmful, while Ferris (1999) claimed error-correcting feedback can help improve the accuracy of students' language forms. The controversy between the two attracts wide attention in academia, and the quantity of empirical studies on the effect of error-correcting feedback is also increasing. Not only is it confined to error-correcting feedback, but also non-error feedback has received widespread interest Under this situation, research on the guidance effect of teacher feedback has become a trend and necessity nowadays. In the paper, the author focuses on the frequency of different ways of feedback that supervisor used, the focus of feedback, and the effect of feedback for undergraduate thesis writing.

The purpose of this paper is to make a quantitative and qualitative analysis of the supervisor's feedback from three aspects: error feedback, non-error feedback and feedback focus, as well as to give some constructive suggestions to teachers. In order to achieve this goal, the paper is divided into four sections: research review of feedback at home and abroad, research design of the paper, quantitative and qualitative analysis of statistical data, inspiration and conclusion of the paper. Through analyzing the foci of feedback methods and their guiding effects, the paper gives teachers a deeper understanding of feedback, and advices on how to adapt to the appropriate feedback methods in future teaching.

\section{Literature Review}

\subsection{Research about Feedback Abroad}

Bitchener (2008) made a 2-month study on the efficacy of written corrective feedback of 75 low intermediate international ESL students in Auckland, New Zealand, and found that the performance accuracy of students who received written corrective feedback in the immediate post-test outperformed those in the control group and that this level of performance was retained 2 months later, which supports that written corrective feedback can benefit EFL learners.

Chandler (2003) found that the accuracy of student writing improved significantly with fewer errors on their revisions. Besides, underlining with description was the easiest way to check the error types and the most beneficial way for students. Bitchener, Cameron and Young (2005) concluded that the combination of written 
and conference feedback had a significant effect on accuracy levels in the use of the past simple tense and the definite article in new pieces of writing.

Through analyzing a total of 35 supervisors across three different disciplines at six New Zealand universities, Bitchener and Basturkmen (2010) found that a wide range of beliefs of feedback are held by supervisors: there is little difference in the type of feedback in different disciplines but salient similarity of feedback given to level 1 and level 2 students. Towards the performance of ESL students in revising writing with corrective feedback, Lee's (1997) findings show that students' major difficulty in error correction lies in their failure to detect errors rather than the lack of knowledge. What's more, students have limited understanding of grammatical terms commonly used in a correction code, so that they correct surface formal errors better than meaning errors.

\subsection{Domestic Research about Feedback}

Yang Y. (2013) studied the effects of feedback on past tense acquisition by English majors and discovered that different feedback suited students of different levels: higher-level learners benefit more from recast feedback, which is more conducive to improving the accuracy of language output; lower-level learners benefit more from prompt feedback which can improve the correctness of the grammatical form. Niu R. and Zhang R. (2018) studied the written feedback of an experienced professional English writing teacher, and found that the teacher's feedback focus was mostly on the language problems of the composition, and the strategies used were mainly indirect feedback.

Li (2013) studied the effectiveness of teacher feedback for a school year in a university. The result showed that both error feedback and non-error feedback can help improve the accuracy of language use in students' compositions, and the latter is more conducive to arouse students' awareness of the deep features of the content and structure of the text. Su (2014) selected five cases of effective feedback and ineffective feedback respectively from 49 English majors to analyze causes for the effectiveness of feedback, discovering that cognitive factors determine the effectiveness greatly, such as grammatical sensitivity and language proficiency determine whether errors can be found, while thinking style and rule inference ability determine the attention or processing depth to feedback and other linguistic forms. Through analyzing the written feedback of an experienced English writing teacher and the multi manuscript compositions of four non-English majors' English writing, Yang L. (2013) found that the influence of teachers' written feedback is not only limited to composition modification, but also had a certain positive impact on the cultivation of students' writing habits and writing attitude.

Li and Deng (2012) confirmed that the vocabulary complexity of learners increased prominently after 16-week writing training, and the sentence complexity remained unchanged, regardless of whether or not they receive feedback and whatever form of feedback they receive, refuting Truscott's view (2007) that teacher's written corrective feedback can reduce learner's writing complexity. Wang Y. and Liu Z. (2012) studied the effects of teacher feedback on second-year English majors' accuracy, fluency, complexity and writing level with qualitative and quantitative methods and concluded that in order to improve these aspects of students' writing, it's essential for teachers to provide feedback on language and content for students to make timely revisions.

\subsection{Research on Error and Non-Error Feedback}

Error correction can be operationalised in terms of direct and indirect correction. (Lee, 1997) Direct correction refers to overt correction of errors-- the teacher provides the correct forms or structures in students' faulty sentences (Hendrickson, 1980). Indirect correction refers to the provision of feedback on errors--prompting students about the location of errors, and/or prompting students about the nature of the errors by means of a correction code (Robb, Ross and Shortreed, 1986). As for the strategies of indirect feedback, Ferris \& Roberts (2001) classified them into four types: circle error; mark the wrong number in the blank; mark the wrong position with symbols; mark the error and indicate the type of error. Concerning the function of error feedback, Ellis (2009) claimed that direct feedback can provide clear guidance for students, while indirect feedback is more conducive to the development of students' second language writing (Ferris, Chaney, Komura, Roberts \& McKee, 2000; Ferris \& Helt, 2000; Ferris, 2003) for it can make students more aware of language forms, mobilize and guide them to participate in problem solving (Ashwell, 2000; Ferris, 2003). Wang H. and Li L. (2014) analyzed 240 compositions written by freshmen in the past 15 weeks, and found that direct feedback can help students to reduce biased questions, discourse coherence and genre errors; indirect feedback can help students to reduce spelling, grammar and vocabulary errors.

The existing research on non-error correction feedback mainly links teacher's comment with student's composition revision. (Ferris, 1997) Tunstall \& Gipps (1996) divided teacher comment feedback into two categories: evaluation type (involving value judgment) and description type (describing what students say or do). 
Ferris and Hedgcock (2005) pointed out that second language learners were susceptible to teacher comments; Hyland \& Hyland (2001) found that even some comments are prone to bring about negative effects on students' writing revision due to the vague expression and scribbled writing, which they may reduce the quality of articles.

Most of the previous research are directed at ESL (English as a second language), a few of which focus on the guidance of academic paper writing in China. In this background, the study investigates the role of supervisor feedback in undergraduate paper revision from the aspects of error feedback, non-error feedback and feedback focus, rephrased as the following questions: What are the main respects that teachers will take in feedback and what is the degree of students' acceptance of feedback?

\section{Research Design}

\subsection{Participants}

The participants are a university teacher and 30 English undergraduate students that the teacher has supervised within the past four years of a college in Jiangxi Province. Their mother tongue is Chinese, and they have been studying English for different periods of time, averaging 10 years.

The English proficiency of the 30 subjects is quite distinctive, which affects their performance in the process of revising papers. Based on students' language skills involved in their thesis, their comprehension and adoption of supervisor feedback and the overall effect of the final revision of their paper, the author selected eight students as major subjects ultimately, including students with strong or weak capability.

\subsection{Data Collection}

The author collected all the electronic papers of the 30 students' theses for Bachelor of Arts throughout their writing process. After careful consultation, eight students of different years were selected as the final subjects. The electronic manuscripts of the eight students' papers were relatively complete and the feedback from their supervisor remained intact. Each thesis has been revised for three times; thus, in total 32 undergraduate theses are taken as research samples finally.

\subsection{Data Analysis}

Combining with the revisions of the researched theses, based on Ellis'(2009) six type of feedback, this study takes reference of six sub-categories: direct error feedback; indirect error feedback: a. indicating the error and its position; b. noting errors implicitly; c. identifying errors with error codes, for example, "Relatively simple way of teachers' questioning (n. is preferred rather than adj.)"; d. noting the mistakes and providing brief descriptive tips, for example, “...32.2\% students say that they just feel so so about English ("just so so is colloquial; it must be expressed in professional terms or degree words)"; re-expression.

Non-error feedback works as comments among these theses. Each kind of comments has a focus: language usage, content organization, grammar mistake and so on. This paper classifies non-error feedback into four kinds according to the focus: comments on the content, comments on organizational structure; comments on grammar or language use; overall improvement tips.

Based on the thesis data and Hyland \& Hyland's (2006) research, the author regards structure, language, logic, demonstration and format as feedback foci in this study, and attaches each feedback with a focus to make deeper research. If one type of feedback contains more than one focus, it is subdivided until it includes only one point. Take one revision tip as an example: "The language used in this paragraph is vague, and the academic style is preferred; the font size is too small." This feedback includes both language and format foci, so it is subdivided into two, linguistic feedback and format feedback to ensure that there are no omissions and duplication in the statistical process.

In the analysis process, the author counts the number of different kinds of feedback and the number of key points in each feedback firstly; then the author counts the aggregate of each feedback focus. The data are analyzed from four aspects: quantity and percentage of different feedback and its sub-kinds; quantity and percentage of feedback focus; the change of each draft in different aspects of feedback; quantity and percentage of feedback types corresponding to different aspects of feedback.

\section{Results and Discussion}

Table 1 shows that in 32 revisions, supervisors used error feedback 274 times, accounting for $64.2 \%$ in the total number of feedback, and non-error feedback for 153 times, accounting for $35.8 \%$.

Among error feedback, the usage of direct error feedback, such as "accessing" changed into "access", "decades" changed into "decades of", is the highest, up to $55.1 \%$, Lee (1997) indicated that students were better at revising 
surface formal errors, which may result in the situation of high frequency use of direct feedback. In the four types of indirect error feedback, "Identifying the error and its position" accounts for the highest proportion, up to $28.5 \%$ followed by "just pointing out the existence of errors", up to $11.3 \%$. The remaining three forms are used less frequently mainly due to their complexity and time consumption. This result is consistent with Li's (2013) research, while it is contrary to Niu's (2018) study. In non-error feedbacks, "comments on organizational structure revision" was used the most frequently (up to $35.3 \%$ ), followed the percentage of $31.4 \%$ for "comments on the content", for example, "“The references should be diversified, including monograph and master's thesis.". The third frequently used is "comments on grammar or language use" (up to 22.2\%) followed by "overall improvement tips", up to $11.1 \%$, while in Li's (2013) research, "comments on contents" occupy the main position, and then is "comments on grammar or language use", "comments on organizational structure revision" is in the third place.

As for the qualitative guidance effect comparing the revised papers with previous ones, it is found that the revised sentences are more precise in language use, like the former informal phrase "just so so" changed into "moderately"; the expression is more refined, like the illogical form "the someone's vocabulary learning ability" changed into "vocabulary learning ability"; the grammatical structure is more acceptable, without common errors, like the absence of articles and subjects.

The effect of non-error feedback on paper revision is multifaceted. From a linguistic point of view, non-error feedback aims at the linguistic rationality of the whole text rather than a specific sentence; in terms of a paragraph, non-error feedback focuses on logic, which makes the paragraph more logical and concise, and enhances the relevance of the context; in terms of the overall framework, non-error feedback can modify the structure of the whole paper, including its demonstration and theoretical basis. The revised papers have more rigorous language, more rational structure, more sufficient demonstration, more appropriate logic and clearer organization.

Table 1. The quantity and percentage of different feedback and its sub-kinds

\begin{tabular}{lcclcc}
\hline \multicolumn{1}{c}{$\begin{array}{c}\text { Error feedback } \\
274(64.2 \%)\end{array}$} & & & \multicolumn{3}{c}{$\begin{array}{c}\text { Non-error feedback } \\
153(35.8 \%)\end{array}$} \\
\hline $\begin{array}{l}\text { 1) Direct error feedback } \\
\text { 2)a Indicating the error and its }\end{array}$ & 78 & $55.1 \%$ & 1) Comments on the content & 48 & $31.4 \%$ \\
position & $28.5 \%$ & $\begin{array}{l}\text { 2) Comments on organizational } \\
\text { structure }\end{array}$ & 54 & $35.3 \%$ \\
2)b Noting errors implicitly & 31 & $11.3 \%$ & $\begin{array}{l}\text { 3) Comments on grammar or } \\
\text { language use }\end{array}$ & 34 & $22.2 \%$ \\
$\begin{array}{l}\text { 2)c Identifying errors with error } \\
\text { codes }\end{array}$ & 6 & $2.2 \%$ & 4) Overall improvement tips & 17 & $11.1 \%$ \\
$\begin{array}{l}\text { 2)d Noting the mistakes and } \\
\text { providing brief descriptive tips }\end{array}$ & 1 & $0.4 \%$ & & & \\
3) Re-expression & 7 & $2.5 \%$ & & & \\
\hline
\end{tabular}

This paper presents the guidance effect of supervisor's feedback from five aspects: structure, language, logic, demonstration and format. The feedback on language counts the highest proportion, up to $48 \%$, followed by format, up to 30\%. Niu and Zhang (2018) also claimed in their research that teachers' feedback focused more on language than content and structure. It can be seen that the primary focus of supervisor feedback is on language and format, and students make more mistakes in these two aspects than others. The proportion of suggestions given in the structure remains in the lowest places. Feedback in logic and demonstration of the paper are the same. The proportion of feedback in logic and demonstration are equally $7.5 \%$ (See Table 2 ). 
Table 2 . The quantity and percentage of feedback focus

\begin{tabular}{ccc}
\hline & Total & Percentage \\
\hline Structure & 30 & $7 \%$ \\
Language & 205 & $48 \%$ \\
Logic & 32 & $7.5 \%$ \\
Demonstration & 32 & $7.5 \%$ \\
Format & 128 & $30 \%$ \\
Total & 427 & $100 \%$
\end{tabular}

Figure 1 shows the quantitative changes of the feedback from different aspects given by supervisors to different revisions of students' papers. Generally speaking, as students constantly revise their papers based on the supervisor's suggestions, error rate in the papers gradually decreases, so does the number of feedback. Li's (2013) study got the same result. However, from figure 1, we find that language and format problems still exist in the fourth draft paper, which occupy a large proportion, which means that these problems need to be revised repeatedly by the students for a long time, taking a great effort, while in Li's (2013) research, in students' final draft, feedback in the contents occupied the most proposition, then were language and structure.

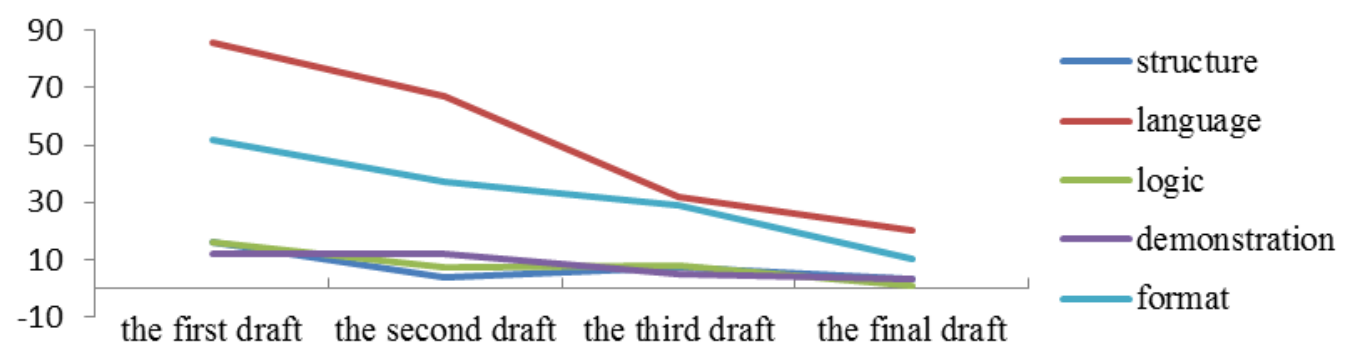

Figure 1. The change of each draft in different aspects of feedback

As is shown in table 3, the suggestions of structure, logic and demonstration of the researched paper revisions are all reflected by non-error feedback, while language and format problems can be modified either by error feedback or by non-error feedback, and the former dominates the main place,. The reason is that non-error feedback pays more attention to the content and the overall framework of the paper rather than the details, so it can be used more effectively in giving advice. Li (2013) declared that both error feedback and non-error feedback can improve the accuracy rate of language usage in writing, and non-error feedback was more conducive to the content and structure, what's more, Chandler (2003) and Bitchener (2008) concluded that error feedback had great improvement in the accuracy and fluency of students' writing. All of their results are consistent with this paper.

The structure of the paper can be more concise and more compact under the guidance from the supervisor, and priority and secondary distinction can be made well, which can fairly clarify the theme of the paper. Logic problem is often related to content logic in the study, and students can make the content more coherent and reasonable than under directives from teachers. The logic also becomes more rigorous. Feedback in demonstration offers students an orientation in enriching the body of their paper, and adds convincing analysis, supplying enough support for the authenticity of the conclusions in the paper.

Although both types of feedback can focus on language, their scope of use is distinctive. Error feedback refers to more specific linguistic or grammatical errors, such as the use of gerunds, prepositions, articles; non-error feedback is directed at the language problem of a paragraph or a section, which aims to make the language of revised paper more precise, clear, fluent, concise and accurate. Concerning about format, among 32 manuscripts in this study, each one contains feedback on it, and many errors have been emphasized again and again, such as font, font size and line spacing these fields. It needs a lot of care and patience to modify these problems compliance with standards, only after many times revisions, can the final paper be more standardized, professional and academic. 
Table 3. The quantity and percentage of feedback types corresponding to feedback focus

\begin{tabular}{ccccc}
\hline & \multicolumn{2}{c}{ Error feedback } & \multicolumn{2}{c}{ Non-error feedback } \\
\hline Structure & 0 & $0 \%$ & 30 & $100 \%$ \\
Language & 166 & $81 \%$ & 39 & $19 \%$ \\
Logic & 0 & $0 \%$ & 32 & $100 \%$ \\
Demonstration & 0 & $0 \%$ & 32 & $100 \%$ \\
Format & 108 & $84.4 \%$ & 20 & $15.6 \%$ \\
\hline
\end{tabular}

\section{Suggestions and Conclusions}

Over the years, feedback has been a remarkable part of teaching. Teacher feedback is of great significance in the improvement of students' overall writing ability and reducing writing difference. (Bitchener, 2005; Chandler, 2003; Tunstall, 1996) Thus, it's extremely essential for supervisors to understand the necessity of feedback.

The study discovers that various feedback methods have different points of foci; moreover, their feedback effect is quite distinctive. Besides, examples of direct feedback combined with indirect feedback in the research have got significant effect. Therefore, in practice, the use of feedback strategies should be variable and not uniform, and wield different types of feedback at the same time will promote the guidance effect.

Some crucial points that teachers should pay attention to in giving feedback may be hinted. Feedback that focuses more on details makes it easier for students to accept and follow, while some broader content makes it ambiguous for students to understand. Feedback may not be taken in the form of questions, declarative sentences that simply and clearly express the supervisor's point of view is quite feasible; last but not least, feedback plays a guiding role for learners, not a decisive role in their thought, and it is a student-centered process. Thus, it is indispensable for teachers to realize students' characteristics and their learning levels. They hopefully mainly work as the instructor or participant rather than leader when offering feedback, and make sure that students need to have their own ideas.

The limitation of this study is that there are not enough papers collected, so the number of supervisor feedback is not sufficient. There may be some subjective factors that lead to data deviation when the author distinguishes the types and foci of feedback. In the future research, a more detailed and accurate classification of feedback can be formulated to make a deeper study, and the interviews with students can be applied to directly understand the impact of teachers' feedback on their writing capability.

\section{References}

Ashwell T. (2000). Patterns of teacher response to student writing in a multiple-draft composition classroom: Is content feedback followed by form feedback the best method? Journal of Second Language Writing, 227-258. https://doi.org/10.1016/S1060-3743(00)00027-8

Bitchener J. (2008). Evidence in support of written corrective feedback. Journal of Second Language Writing, 102-118. https://doi.org/10.1016/j.jslw.2007.11.004

Bitchener J. \& Basturkme H. (2010). The focus of supervisor written feedback to thesis/dissertation students. International Journal of English Studies, 79-97. https://doi.org/10.6018/ijes.10.2.119201

Bitchener J., Cameron D. \& Young S. (2005). The effect of different types of corrective feedback on ESL student writing. Journal of Second Language Writing, 191-205. https://doi.org/10.1016/j.jslw.2005.08.001

Chandler J. (2003). The efficacy of various kinds of error feedback for improvement in the accuracy and fluency of L2 student writing. Journal of Second Language Writing, 267-296. https://doi.org/ 10.1016/S1060-3743(03)00038-9

Ellis R. (2009). A typology of written corrective feedback types. ELT Journal, 97-107. https://doi.org/ $10.1093 / \mathrm{elt} / \mathrm{ccn} 023$

Ferris D. R. (1997). The influence of teacher commentary on student revision. TESOL Quarterly, 315-339. https://doi. org/10.2307/3588049 
Ferris D. R. (1999). The case for grammar correction in L2 writing classes: A response to Truscott. Journal of Second Language Writing, 1-10. https://doi. org/10.1016/S1060-3743(99)80110-6

Ferris D. R. (2003). Response to student writing: implications for second language students. Mahwah, NJ: Lawrence Erlbaum Associates.

Ferris D. R., Chaney S. J., Komura K., Roberts B. J. \& McKee S. (2000). Perspectives, problems, and practices in treating written error. Vancouver: The International TESOL Convention.

Ferris D. R. \& Hedgcock J. S. (2005). Teaching ESL composition: purpose, process, and practice. Mahwah, NJ: Lawrence Erlbaum Associates.

Ferris D. R. \& Helt M. (2000). Was Truscott right? New evidence on the effects of error correction in L2 writing classes. Vancouver: The AAAL Conference.

Ferris D. R. \& Roberts B. (2001). Error feedback in L2 writing classes: How explicit does it need to be? Journal of Second Language Writing, 161-184. https://doi.org/10.1016/S1060-3743(01)00039-X

Hendrickson J. M. (1980). The treatment of error in written work. Modern Language Journal, 216-221. https:// doi.org/10.1111/j.1540-4781.1980.tb05188.x

Hyland F. \& Hyland K. (2001). Sugaring the pill: Praise and criticism in written feedback. Journal of Second Language Writing, 185-212. https://doi.org/10.1016/S1060-3743(01)00038-8

Hyland F. \& Hyland K. (2006). Interpersonal aspects of response: Constructing and interpreting teacher written feedback. Cambridge: Cambridge University Press.

Keh C. L. (1990). Feedback in the writing process: a model and methods for implementation. ELT Journal, 294-304. https://doi.org/10.1093/elt/44.4.294

Lee I. (1997). ESL learners' performance in error correction in writing: Some implications for teaching. Elsevier Science Ltd, 465-477. https://doi.org/10.1016/S0346-251X(97)00045-6

Li J. (2013). A case study on the effect of teachers' written feedback in English writing teaching. Foreign Language Circles, 87-96. https://doi.org/CNKI:SUN:WYJY.0.2013-02-012

Li Y. \& Deng H. (2012). The influence of teachers' written corrective feedback on the complexity of English writing. Foreign Language Research, 55-62. https://doi.org/10.13978/j.cnki.wyyj.2012.02.019

Niu R. \& Zhang R. (2018). A case study on the focus, strategy and effectiveness of written feedback of L2 writing teachers. Journal of PLA University of Foreign Languages, 91-99. https://doi.org/CNKI:SUN:JFJW.0.2018-03-012

$\mathrm{Su}$ J. (2014). The relationship between cognitive factors, attention and written corrective feedback effect. $\begin{array}{lllll}\text { Journal of Xi'an International } & \text { Studies }\end{array}$ https://doi.org/10.3969/j.issn.1673-9876.2014.01.018

Thomas R. (1986). Steven R. \& Shortreed I., Salience of feedback on error and its effect on ESL writing quality. TESOL Quarterly, 83-95. https://doi. org/10.2307/3586390

Truscott J. (2007). The effect of error correction on learners' ability to write accurately. Journal of Second Language Writing, 1-18. https://doi.org/10.1016/j.jslw.2007.06.003

Tunstall P., \& Gipps C. (1996). Teacher feedback to young children in formative assessment: A typology. British Educational Research Journal, 389-404. https://doi.org/10.1080/0141192960220402

Wang Y., \& Liu Z. (2012). Research on the effect of teacher feedback on the accuracy, fluency, complexity and overall quality of English writing. Foreign Language Teaching, 49-53. https://doi.org/10.16362/j.cnki.cn61-1023/h.2012.06.019

Wu W. (2015). The interactive influence of teachers' feedback focus and feedback strategies on the effect of English writing modification. Journal of PLA University of Foreign Languages, 85-93.

Wang H., \& Li L. (2014). The influence of direct feedback and indirect feedback on students' English writing quality. Foreign Language Education \& $\quad$ Research, 38-44. https://doi.org/10.16739/j.cnki.cn21-9203/g4.2014.01.011

Yang Y. (2013). An empirical study on the effect of feedback on the development of target language of learners at different levels. Foreign Language Teaching, 73, 59-62, https://doi.org/10.16362/j.cnki.cn61-1023/h.2013.03.024 
Yang L. (2013). A case study of the influence of teachers' written feedback on college students' English writing learning. Shandong Foreign Language Teaching Journal, 12-18. https://doi.org/10.16482/j.sdwy37-1026.2013.05.014

\section{Copyrights}

Copyright for this article is retained by the author(s), with first publication rights granted to the journal.

This is an open-access article distributed under the terms and conditions of the Creative Commons Attribution license (http://creativecommons.org/licenses/by/4.0/). 